\title{
Syntheses, Characterizations and Luminescent Properties of Three 3D Lead-Organic Frameworks with 1D Channels
}

Ya-Hui Zhao, ${ }^{\dagger}$ Hong-Bin Xu, ${ }^{\dagger}$ Kui-Zhan Shao, ${ }^{\dagger}$ Yan Xing, ${ }^{\dagger}$ Zhong-Min Su, ${ }^{* \dagger}$ and Jian-Fang Ma ${ }^{*,}$ Institute of Functional Material Chemistry, Faculty of Chemistry, Northeast Normal University, Changchun, 130024, People's Republic of China.

Faculty of Chemistry, Northeast Normal University, Changchun 130024, People's Republic of China

\section{Supporting information}

Synthesis of HINO: The mixture of isonicotinic acid (3.69 g, $30.0 \mathrm{mmol})$, glacial acetic acid $(75 \mathrm{ml})$, and $30 \%$ hydrogen peroxide $(13 \mathrm{ml})$ were heated at $70-80^{\circ} \mathrm{C}$ for 3 hours. An additional $9 \mathrm{ml}$. of hydrogen peroxide was added and the temperature maintained at $70-80^{\circ} \mathrm{C}$ for 19 hours. On addition of acetone was added, and then the white needle crystal precipitated at $0^{\circ} \mathrm{C}$ for several hours. Yield: $2.59 \mathrm{~g}(82 \%) .{ }^{1} \mathrm{H}$ NMR (DMSO- $\left.d 6\right) \delta 13.1$ (br s, OH), 8.96 (s, 2H), 7.87 (s, 2H). IR $\left(\mathrm{KBr} \mathrm{cm}^{-1}\right) 1609(\mathrm{~s}), 1568(\mathrm{~m}), 1482(\mathrm{w}), 1434(\mathrm{~m}), 1321(\mathrm{~m}), 1198(\mathrm{~s}), 1096(\mathrm{~m}), 925(\mathrm{~m}), 758(\mathrm{~s})$, 669 (w), 564(w). Anal. Calcd for $\mathrm{C}_{6} \mathrm{H}_{5} \mathrm{NO}_{3}$ : C, 75.46; H, 4.43. Found: C, 75.57; H, 4.48. 

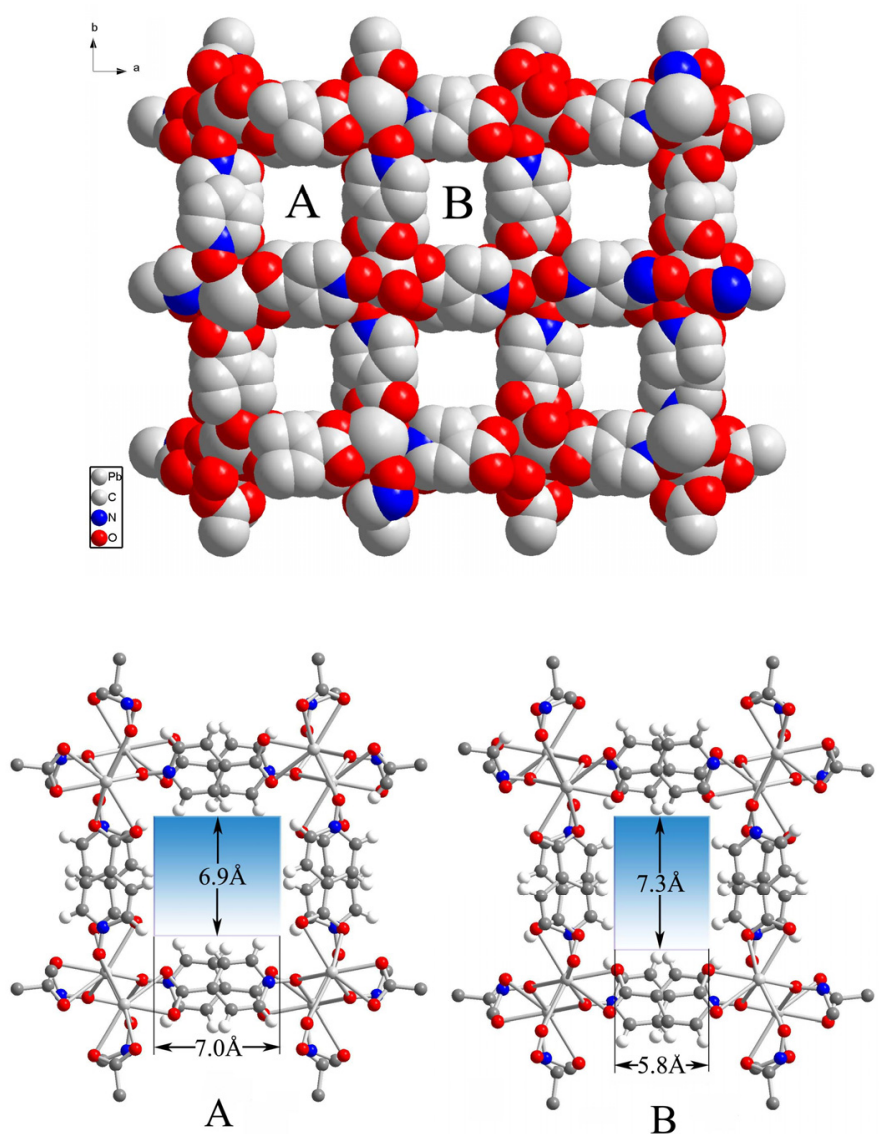

Figure S1. Space-filling representation of evacuated framework 1, which emphasizes the two distinct channels ( $\mathbf{A}$ and $\mathbf{B}$ ), view along the $c$-axis. The guest molecules in the channels are omitted for clarity. Bottom: dimensions of two channels.

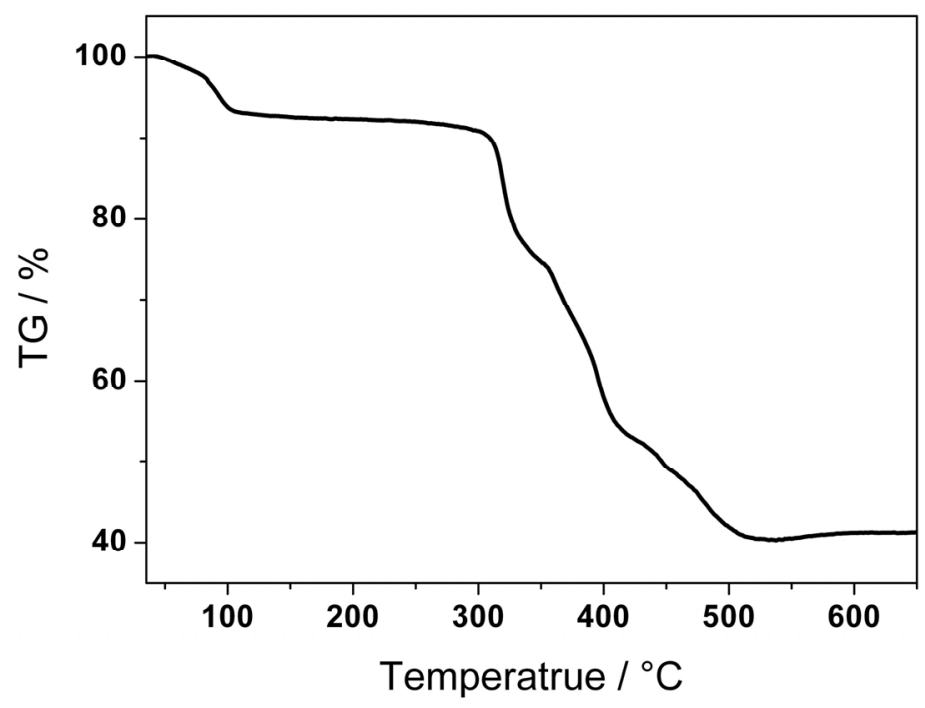

Figure S2. TGA curve of $\mathbf{1}$. 


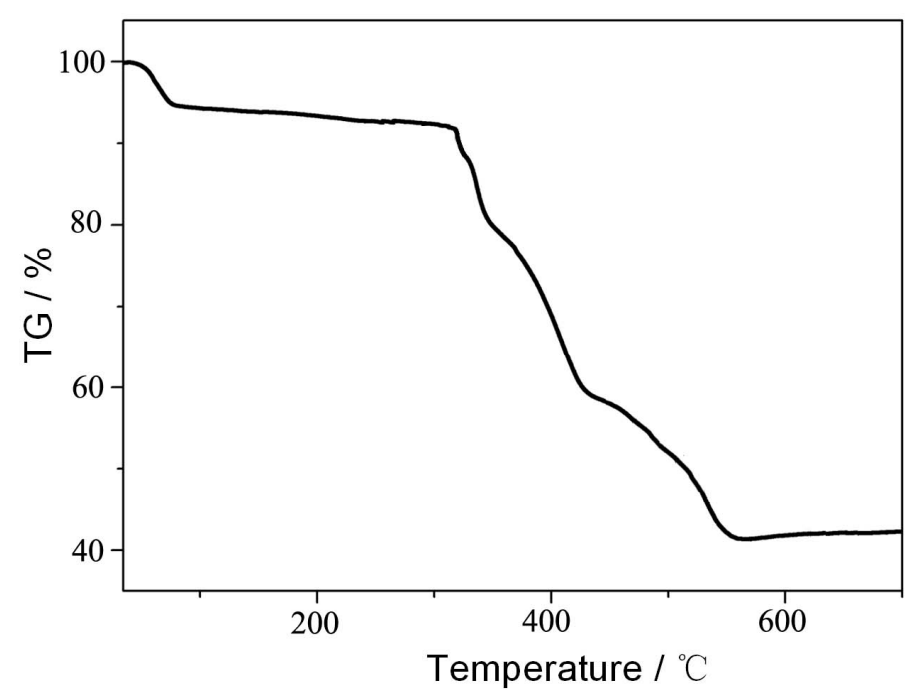

Figure S3. TGA curve of 2.

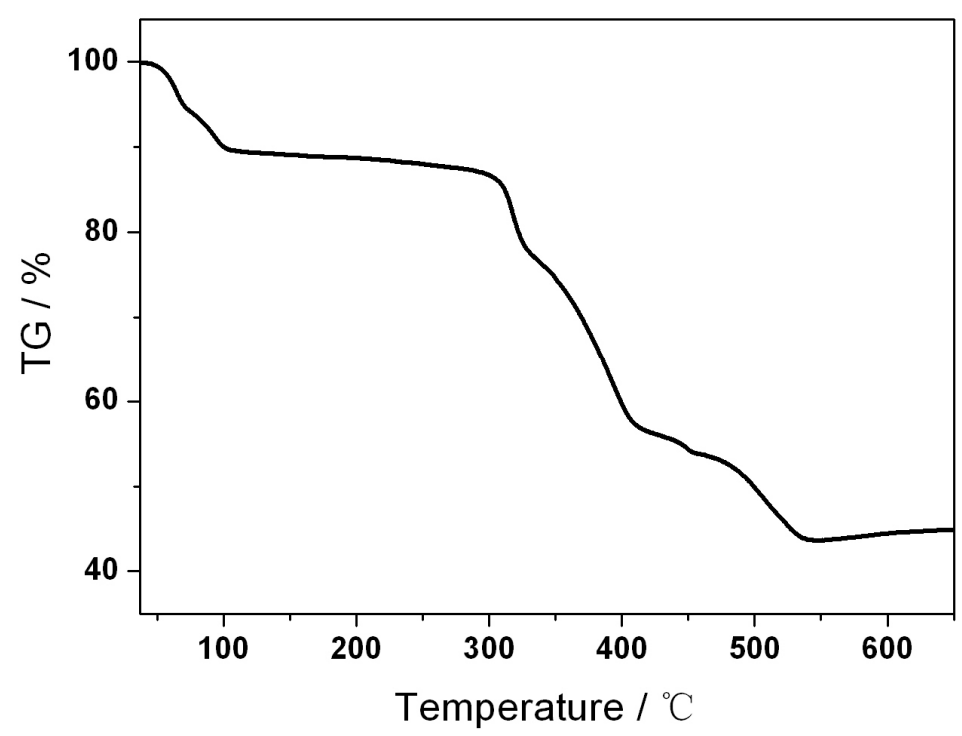

Figure S4. TGA curve of 3. 


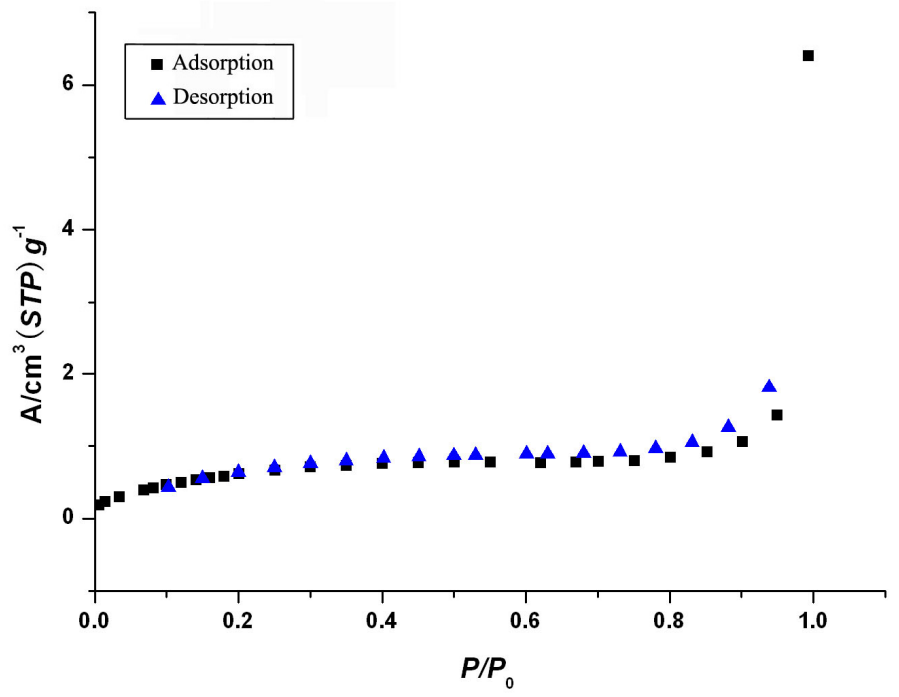

Figure S5. Isotherms for the adsorption and desorption of $\mathrm{N}_{2}$ at room temperature for 3 . Herein, A refers to absolute adsorption and STP to standard temperature and pressure. 